\title{
Influence of pile inclination angle on the dynamic properties and seismic response of piled structures *
}

\author{
Cristina Medina, Luis A. Padrón, Juan J. Aznárez, Orlando Maeso \\ Instituto Universitario de Sistemas Inteligentes y Aplicaciones Numéricas en Ingeniería \\ (SIANI) Universidad de Las Palmas de Gran Canaria \\ Edificio Central del Parque Científico y Tecnológico \\ Campus Universitario de Tafira, 35017, Las Palmas de Gran Canaria, Spain \\ \{cmedina, jjaznarez, lpadron, omaeso\}@siani.es, web: http://www.siani.es
}

24 October 2014

\begin{abstract}
This paper aims to contribute to clarify whether the use of battered piles has a positive or negative influence on the dynamic response of deep foundations and superstructures. For this purpose, the dynamic response of slender and non-slender structures supported on several configurations of $2 \times 2$ and $3 \times 3$ pile groups including battered elements is obtained through a procedure based on a substructuring model which takes soil-structure interaction into account. Results are expressed in terms of flexible-base period and maximum shear force at the base of the structure. Moreover, modified response spectra considering soil-structure interaction effects are provided for different rake angles. It is shown that an increment of the rake angle can result in beneficial or detrimental effects depending on the structural slenderness ratio.
\end{abstract}

Keywords: Inclined piles, Piled foundations, Soil-structure interaction, Effective period, Effective damping, Substructure model, Seismic response

\section{Introduction}

The dynamic behaviour of buildings is affected by kinematic and inertial effects associated to soilstructure interaction (SSI). Their influence on the fundamental period and damping of soil-structure systems have been broadly investigated for shallow foundations [1-6] as well as for embedded foundations, either considering only inertial interaction (e.g. 7, 81) or taking also into account the modified foundation input motion defined by kinematic interaction [9 13]. A few studies [14 23] analysing the effects of SSI on the dynamic characteristics of pile-supported structures can also be found in the scientific literature . Furthermore, up to the author's knowledge, only Gerolymos et al. [24] and

${ }^{*}$ Draft of the paper originally published in Soil Dynamics and Earthquake Engineering 2015; 69:196-206. http://dx.doi.org/10.1016/j.soildyn.2014.10.027. This work is released with a Creative Commons Attribution Non-Commercial No derivatives License. 
Giannakou et al. [25] have analysed the influence of using deep foundations with inclined piles on the dynamic response of the structure they support.

In recent years, inclined piles have recovered their popularity. Indeed, several studies has shown the beneficial role of battered piles on the seismic response of the structure [24, 26 28]. However, further research is needed to be able to elucidate in which cases the presence of raked piles is beneficial or detrimental.

The aim of this work is to evaluate the influence of the rake angle on the dynamic response of shear structures founded on square pile groups comprising inclined piles and embedded in homogeneous viscoelastic half-spaces subjected to vertically incident $\mathrm{S}$ waves. The analysis is addressed through a simple and accurate procedure [23] based on a substructuring model in the frequency domain that takes into account kinematic and inertial interaction effects. A boundary element-finite element (BEMFEM) formulation 29 31] has been used to compute the impedance functions and the kinematic interaction factors.

Results for several configurations of $2 \times 2$ and $3 \times 3$ pile groups including battered elements are obtained. The seismic response of the superstructure is presented in terms of the effective period and the maximum shear force at the base of the structure per effective earthquake force unit $Q_{m}$. Moreover, results in terms of effective period and damping are used to build modified response spectra for different values of the rake angle.

\section{Methodology}

The dynamic behaviour of linear shear structures supported on pile groups and subjected to vertically incident plane $\mathrm{S}$ waves is analysed in this paper by using a three-degree-of-freedom (3DOF) system as the one depicted in Fig. 1a. This system is defined by the foundation horizontal displacement $u^{c}$ and rocking $\varphi^{c}$, together with the structural horizontal deflection $u$.

(a)

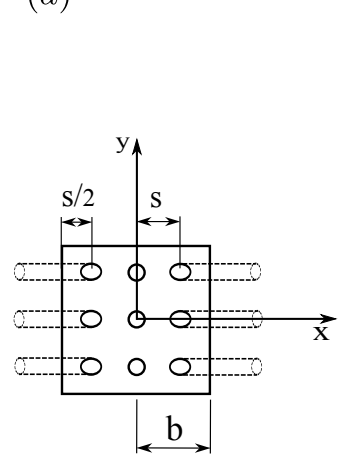

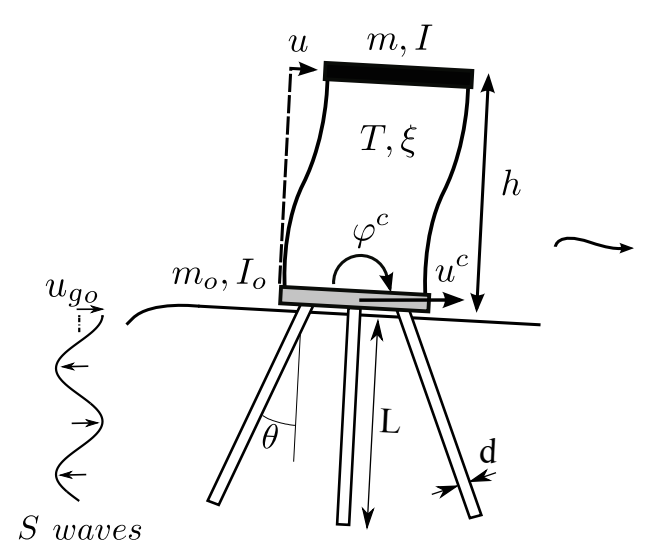

(b)

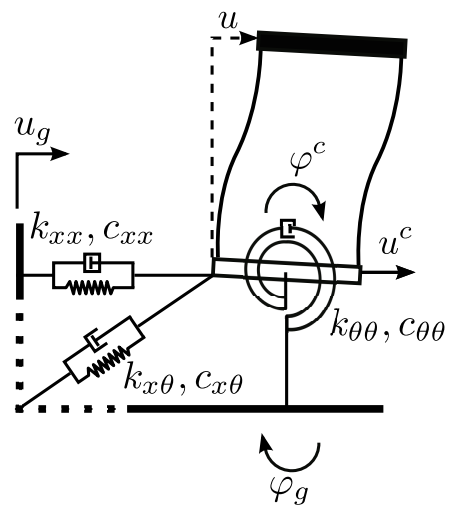

(c)

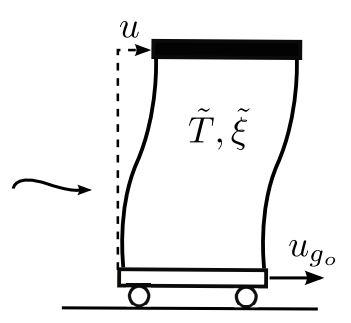

Figure 1: (a) Problem definition (b) substructure model of a one-storey structure and (c) equivalent single-degree-of-freedom oscillator.

The structure is considered to be founded on a square regular group of piles embedded in a 
homogeneous, viscoelastic and isotropic halfspace. Pile heads are constrained to a rigid square cap of negligible thickness and mass $m_{o}$, which is free of contact with the ground surface. The moment of inertia of this pile cap is denoted by $I_{o}$. All piles have identical geometrical properties defined by length $L$ and sectional diameter $d$. Several configurations of pile groups have been considered in this study. Each one of them is defined by number of piles, foundation halfwidth $b$, centre-to-centre spacing between adjacent piles $s$ and rake angle of piles $\theta$. It is worth noting that some vertical piles are included in $3 \times 3$ pile groups for the purpose of maintaining symmetry with respect to planes $x z$ and $y z$.

The superstructure consists of massless and axially inextensible columns that support the structural mass $m$, which is situated at the height $h$ of the resultant of the inertia forces for the mode of vibration under study. The moment of inertia of the vibrating mass, which is distributed over a square area, is denoted by $I$. Its dynamic behaviour, corresponding to fixed-base condition, is characterized by the structural stiffness $k$ and its viscous damping ratio $\xi$.

The 3DOF system dynamic response, considering kinematic and inertial interaction effects, can be studied through a substructuring model in the frequency domain such as that represented in Figure 10. This model consists of a building-cap structure supported on springs and dashpots representing the soil-foundation stiffness and damping in the horizontal $\left(k_{x x}, c_{x x}\right)$, rocking $\left(k_{\theta \theta}, c_{\theta \theta}\right)$ and crosscoupled horizontal-rocking $\left(k_{x \theta}, c_{x \theta}\right)$ vibration modes, respectively. The whole system is subjected to the horizontal $\left(u_{g}\right)$ and rocking $\left(\varphi_{g}\right)$ motions measured at the massless pile cap level when subjected to free-field motion at the surface $u_{g_{o}}$.

In this paper, a BEM-FEM coupling model [28-31] is used to compute translational $I_{u}=u_{g} / u_{g_{o}}$ and rotational $I_{\varphi}=\varphi_{g} b / u_{g_{o}}$ kinematic interaction factors, as well as impedance functions at each frequency $a_{o}$, which are usually written as $K_{i j}=k_{i j}+\mathrm{i} a_{o} c_{i j}$, where $k_{i j}$ and $c_{i j}$ are the mentioned frequency-dependent dynamic stiffness and damping coefficients, respectively, $i=\sqrt{-1}$ is the imaginary unit. The dimensionless excitation frequency is defined as $a_{o}=\omega b / c_{s}$, being $\omega$ the excitation circular frequency, $c_{s}=\sqrt{\mu_{s} / \rho_{s}}$ the speed of propagation of shear waves in the halfspace, and $\mu_{s}$ and $\rho_{s}$ the soil shear modulus of elasticity and mass density, respectively.

Following other authors [2, 3, 8, 12] and in order to characterize the soil-foundation-structure system, other dimensionless parameters, covering the mean features of SSI problems, has been used. These are: (1) structural slenderness ratio $h / b$; (2) fixed-base structure damping ratio $\xi$; (3) dimensionless fixed-base natural frequency of the structure $\lambda=\omega_{n} / \omega ;(4)$ foundation-structure mass ratio $m_{o} / m$; (5) wave parameter $\sigma=c_{s} T / h$ (that measures the soil-structure relative stiffness); (6) mass density ratio $\delta=m /\left(4 \rho_{s} b^{2} h\right)$ between structure and supporting soil; (7) Poisson's ratio $\nu_{s}$; and (8) damping ratio $\xi_{s}$ of the soil. A hysteretic damping model of the type $\mu_{s}=\operatorname{Re}\left[\mu_{s}\right]\left(1+2 \mathrm{i} \xi_{s}\right)$ is considered in this study for the soil material.

The dimensionless parameters used to characterize the pile foundation are: pile spacing ratio $s / d$, pile-soil Young's modulus ratio $E_{p} / E_{s}$, size of the square pile group, embedment ratio $L / b$, pile slenderness ratio $L / d$, dimensionless frequency $a_{o}$, soil-pile densities ratio $\rho_{s} / \rho_{p}$ and rake angle $\theta$.

A simple and accurate procedure developed by Medina et al.[23] is used in this paper to determine the dynamic characteristics of an equivalent single-degree-of-freedom (SDOF) oscillator (Fig. 11k) which reproduces, as accurately as possible, the response of the 3DOF system shown in Fig. 10 within the range where the peak response occurs. This response is expressed in terms of $Q=\left|\omega_{n}^{2} u /\left(\omega^{2} u_{g_{o}}\right)\right|$, which represents the ratio of the shear force at the base of the structure to the effective earthquake 
force. The equivalent SDOF system can be defined by its damping ratio $\tilde{\xi}$ and its undamped natural $\operatorname{period} \tilde{T}$.

The effective period $\tilde{T} / T=\tilde{\lambda}=\omega_{n} / \tilde{\omega}_{n}$ can be found as the root of Eq. (1), being $\tilde{\omega}_{n}$ the undamped natural frequency of the equivalent oscillator. The effective damping $\tilde{\xi}$ can be obtained from Eq. (2).

$$
\begin{gathered}
1-\frac{1}{\lambda^{2}}-\frac{1}{\lambda^{2} \alpha_{x x}^{2}(\lambda)}-\frac{1}{\lambda^{2} \alpha_{\theta \theta}^{2}(\lambda)}=0 \\
\tilde{\xi}=\left|\left(I_{u}+\frac{h}{b} I_{\varphi}\right)^{-1}\left[\frac{\xi^{\prime}}{\tilde{\lambda}^{2}}+\frac{1}{\tilde{\lambda}^{2}}\left(\frac{\xi_{x x}}{\alpha_{x x}^{2}\left(1+\mathrm{i} 2 \xi_{x x}\right)}+\frac{\xi_{\theta \theta}}{\alpha_{\theta \theta}^{2}\left(1+\mathrm{i} 2 \xi_{\theta \theta}\right)}\right)\right]\right|
\end{gathered}
$$

80 where,

$$
\begin{gathered}
\xi^{\prime}=\frac{\omega}{\omega_{n}} \xi \\
\alpha_{x x}^{2}=\sigma^{2} \frac{1}{16 \pi^{2}} \frac{h}{b} \frac{1}{\delta} \tilde{k}_{x x} \\
\xi_{x x}=\frac{\tilde{c}_{x x}}{2 \tilde{k}_{x x}} \\
\alpha_{\theta \theta}^{2}=\sigma^{2} \frac{1}{16 \pi^{2}} \frac{h}{b} \frac{1}{\delta} \operatorname{Re}\left[\frac{b^{2}}{(h+D)^{2}} \tilde{K}_{\theta \theta_{D}}\right] \\
\xi_{\theta \theta}=\frac{\operatorname{Im}\left[\frac{b^{2}}{(h+D)^{2}} \tilde{K}_{\theta \theta_{D}}\right]}{2 \operatorname{Re}\left[\frac{b^{2}}{(h+D)^{2}} \tilde{K}_{\theta \theta_{D}}\right]}
\end{gathered}
$$

being $\tilde{K}_{x x}=K_{x x} /\left(\mu_{s} b\right)=\tilde{k}_{x x}+\mathrm{i} \tilde{c}_{x x}$ and

$$
\begin{gathered}
\tilde{K}_{\theta \theta_{D}}=\frac{1}{\mu_{s} b^{3}}\left(K_{\theta \theta}-\frac{K_{\theta x}^{2}}{K_{x x}}\right) \\
\frac{b^{2}}{(h+D)^{2}}=\left(\left(\frac{h}{b}\right)^{2}-2\left(\frac{h}{b}\right) \frac{\tilde{K}_{\theta x}}{\tilde{K}_{x x}}+\left(\frac{\tilde{K}_{\theta x}}{\tilde{K}_{x x}}\right)^{2}\right)^{-1}
\end{gathered}
$$

where $D=D(\omega)=-K_{x \theta} / K_{x x}$ represents the virtual depth of the point at which the soil-foundation interaction must be condensed to obtain a diagonal impedance matrix.

Finally, the maximum shear force at the base of the structure per effective earthquake force unit $Q_{m}$ is obtained as

$$
Q_{m}=\operatorname{Max}\left|\frac{1}{\left(\frac{\omega^{2}}{\omega_{n}^{2}}\left(\frac{\tilde{T}}{T}\right)^{2}-1\right)-i 2 \tilde{\xi} \frac{\omega}{\omega_{n}} \frac{\tilde{T}}{T}}\right|
$$




\section{Results}

The procedure explained above is applied in this section to the study of the influence of using deep foundations with inclined piles on the seismic response of the superstructure. Such influence is measured here in terms of the effective system period $\tilde{T} / T$, the maximum shear force at the base of the structure per effective earthquake force unit $Q_{m}$ and the elastic response spectra.

Table 1: Values for the dimensionless parameters in the cases under investigation

\begin{tabular}{|c|c|c|c|c|c|c|c|c|c|c|c|c|}
\hline \multirow{2}{*}{$\nu_{s}$} & \multirow{2}{*}{$\xi_{s}$} & \multirow{2}{*}{$E_{p} / E_{s}$} & \multirow{2}{*}{$\rho_{p} / \rho_{s}$} & \multirow{2}{*}{$L / b$} & \multirow{2}{*}{$L / d$} & \multicolumn{2}{|c|}{$s / d$} & \multirow{2}{*}{$\xi$} & \multirow{2}{*}{$\delta$} & \multirow{2}{*}{$1 / \sigma$} & \multirow{2}{*}{$m_{o} / m$} & \multirow{2}{*}{$h / b$} \\
\hline & & & & & & $2 \times 2$ & $3 \times 3$ & & & & & \\
\hline \multirow{3}{*}{0.4} & & & & & 7.5 & 3.75 & 2.5 & & & & & \\
\hline & 0.05 & $10^{3}$ & 0.7 & 2 & 15 & 7.5 & 5 & 0.05 & 0.15 & $0-0.5$ & 0 & $1,2,5,10$ \\
\hline & & & & & 30 & 15 & 10 & & & & & \\
\hline
\end{tabular}

Results for different soil-foundation-structure systems as described in Section 2, are studied in the frequency range of interest for seismic loading $\left(\omega d / c_{s}<0.5\right.$, according to Gazetas et al. [32]). The dimensionless parameters corresponding to these configurations are listed in Table 11. These values are representative for typical buildings and soils [12, 33] and are related to those studied in Medina et al. 23], whose aim was analyzing the influence of the pile foundation on the dynamic response of the soil-foundation-structure system, and where several values of the embedment ratio $L / b$ were considered. In contrast, the present work aims to analyse the effect of inclined piles on the structural response (by means of an additional parameter $\theta$ representing the rake angle) and, therefore, an intermediate value of this parameter $L / b=2$ has been chosen as representative. Regarding the structural slenderness ratio $h / b$, the range of values taken into account is similar to those considered in previous studies $2,12,23,25]$. The varying values of the pile spacing ratio $s / d$ are chosen in order to make the different results more comparable among each other by keeping the foundation halfwidth $b$ constant for configurations with different number of piles. The foundation halfwidth is defined as $b=s$ for $2 \times 2$ pile groups and $b=3 s / 2$ for $3 \times 3$ pile groups. Four different rake angles have been considered: $\theta=0^{\circ}$ (vertical piles), $10^{\circ}, 20^{\circ}$ and $30^{\circ}$.

\subsection{Effective period}

Figs. 2 and 3 present $\tilde{T} / T$ as a function of $1 / \sigma$ for different rake angles $\theta$, which illustrates the influence of the rake angle on the system effective period for the different configurations of $2 \times 2$ and $3 \times 3$ pile groups under study. Discrete points to be read on the right axis provide a zoomed view in those cases in which it is necessary.

For short and squat buildings $(h / b=1)$, in which the horizontal displacement is the controlling factor, the system period decreases for higher rake angles. This is because an increment of the rake angle leads to an increase of the horizontal stiffness due to the contribution of the pile axial stiffness to withstand the lateral loads. In order to illustrate this effect, Fig. 4 present the impedances of three different $2 \times 2$ pile groups with $L / d=7.5$ (left column), $L / d=15$ (central column) and $L / d=30$ (right column). The stiffness values $k_{i j}$ are represented with solid lines to be read on the left axis, whereas the damping values $c_{i j}$ depicted with dashed lines to be read on the right axis. 

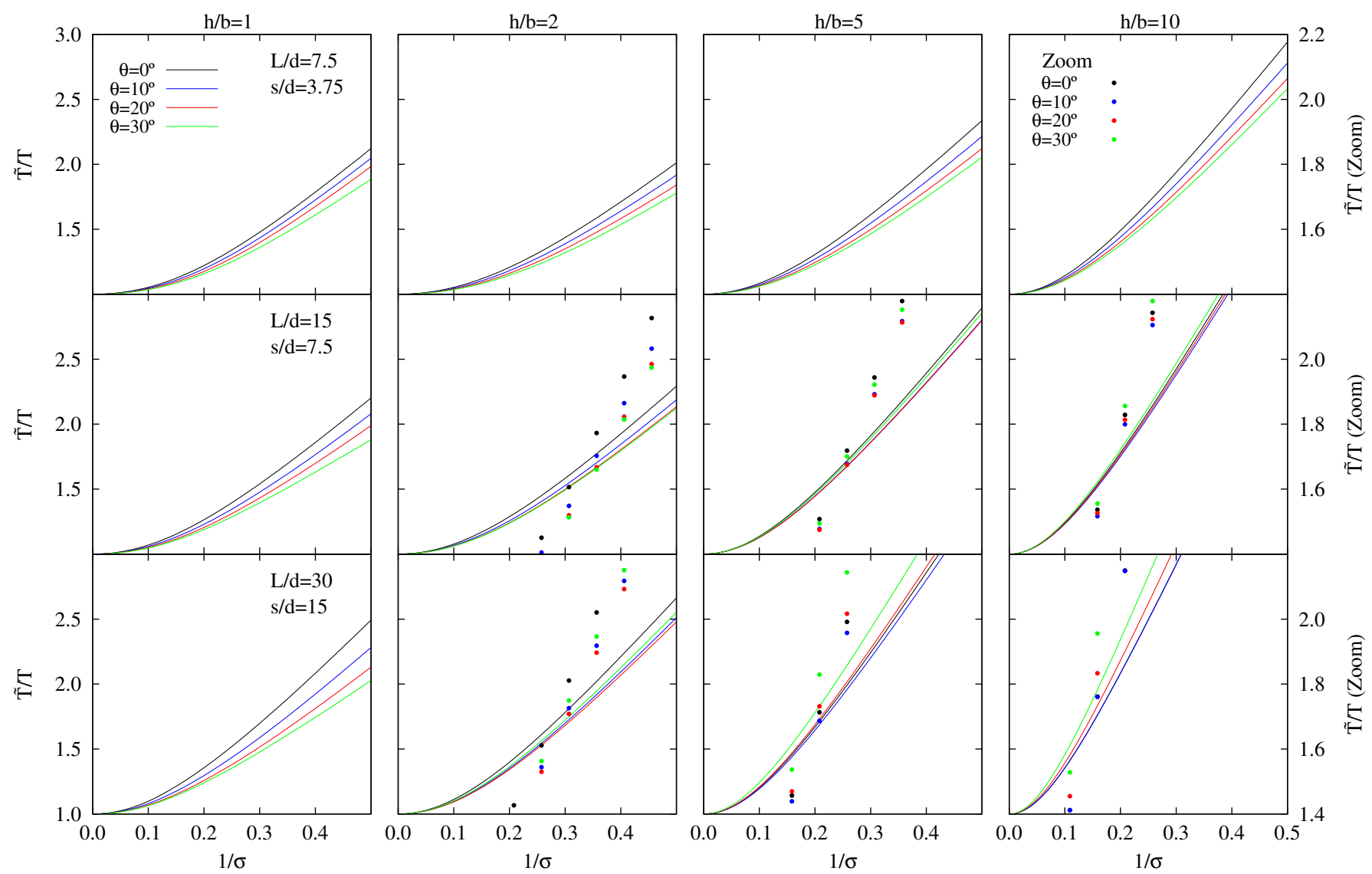

Figure 2: Effective period $\tilde{T} / T$ for different $2 \times 2$ pile groups. $E_{p} / E_{s}=1000$ and $\xi_{s}=0.05$. Solid lines to be read on left axis. Dotted lines to be read on right axis when a zoomed view is needed.

In the case of slender structures $(h / b=10)$, the effect of the rake angle on the system period depends on the variation of the rocking stiffness as well. An increment of the rake angle generally leads to a decrease of the rocking impedance (second row in Fig. (4). This results from the fact that vertical impedance of single piles experiences a reduction when piles are inclined. Exceptionally, in those cases with little spacing between adjacent piles (left column in Fig. (4) the pile-soil-pile interaction effect takes predominance over that of inclination and the vertical impedance of each pile increases with the rake angle since the distance between the pile tips widens with depth. Thus, in those cases in which the increase of the rake angle leads to a reduction of the rocking stiffness $(L / d=15$ and $L / d=30$ ), the system period experiences an increase with $\theta$. Accordingly, a reduction of the system period results from the increase of the rake angle when $L / d=7.5$ since the rocking stiffness increases in this case. 

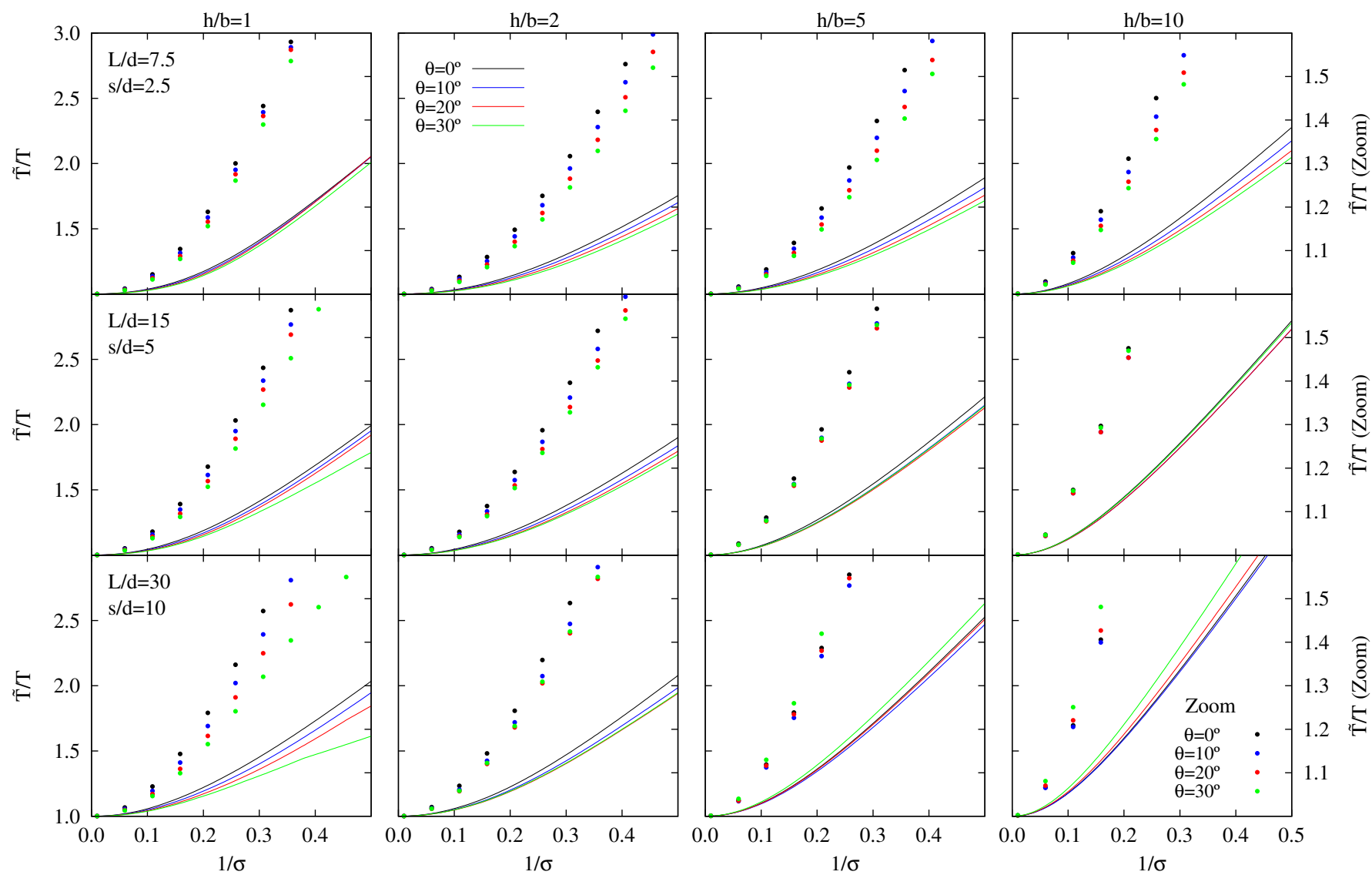

Figure 3: Effective period $\tilde{T} / T$ for different $3 \times 3$ pile groups. $E_{p} / E_{s}=1000$ and $\xi_{s}=0.05$. Solid lines to be read on left axis. Dotted lines to be read on right axis when a zoomed view is needed.

\subsection{Maximum structural shear forces}

Figs. 5 and 6 depict the system response of structures founded on $2 \times 2$ and $3 \times 3$ pile groups, in terms of the maximum shear force at the base of the structure per effective earthquake force unit $Q_{m}$. Dotted lines to be read on the right axis provide a zoomed view in those cases in which it is necessary.

For short and squat buildings $(h / b=1$ and $h / b=2)$, the increment of the rake angle results in lower values of the maximum shear force at the base of the structure. This effect is due to several concurrent factors: an increase of the horizontal damping $c_{x x}$, a reduction of the translational kinematic interaction factor, (which predominates for non-slender structures) and an increase in the horizontal stiffness of the foundation which leads to a reduction of the effective period which, in turn, entails an increment of the dissipated energy which contributes to reduce $Q_{m}$.

In the case of slender structures $(h / b=10)$, an increase of the rake angle leads to slightly greater values of $Q_{m}$ due to the reduction of the rocking damping $c_{\theta \theta}$ and to the increment of the overturning moment, which is the controlling factor in these cases. 

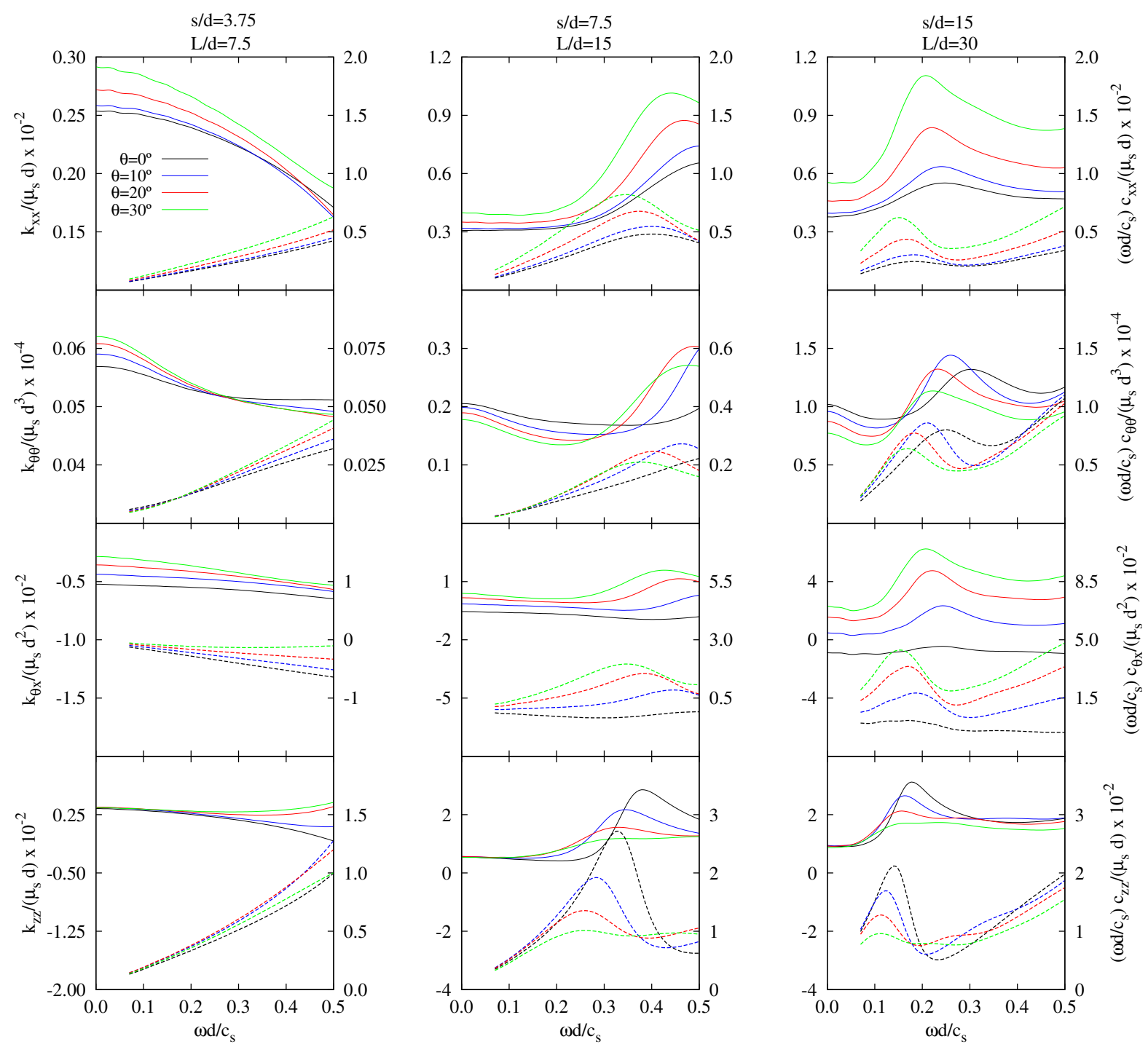

Figure 4: Impedance functions of different $2 \times 2$ pile groups. $E_{p} / E_{s}=1000$ and $\xi_{s}=0.05$. Solid lines to be read on left axis. Dashed lines to be read on right axis.

Fig. 5 allows to show the extent to which kinematic interaction influences the system dynamic response. To this end, results involving both kinematic and inertial interaction or only inertial interaction are represented. It can be seen that the ability of the foundation to filter the seismic input has significant effects on the variation of $Q_{m}$. All configurations under study show a reduction of the translational kinematic interaction factor $I_{u}$ for higher rake angles, as illustrated in Fig. 7 , that presents kinematic interaction factors for three different $2 \times 2$ pile groups with $L / d=7.5$ (left column), $L / d=15$ (central column) and $L / d=30$ (right column). Generally, $I_{\varphi}$ increases significantly with 

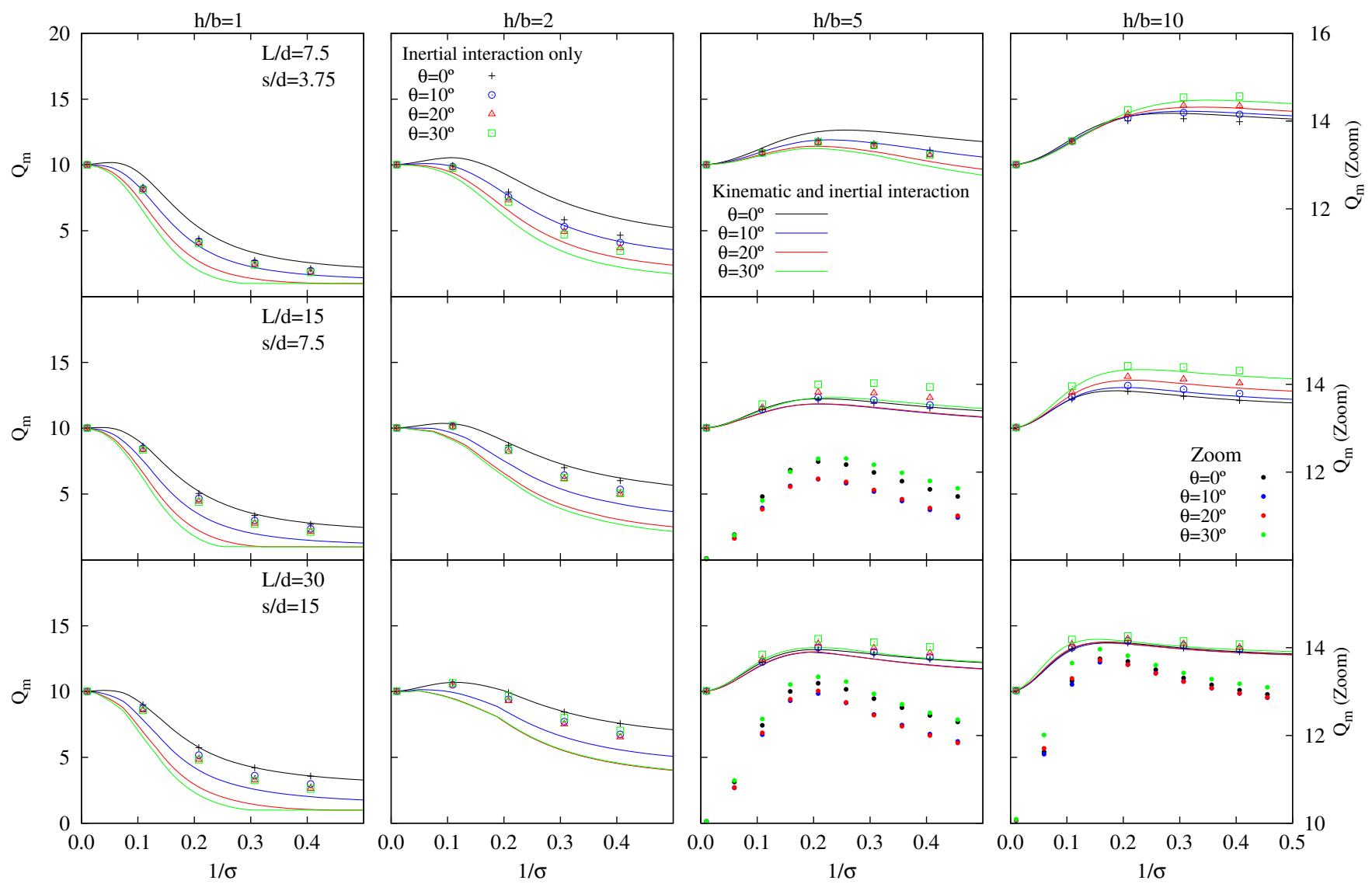

Figure 5: Maximum structural response value $Q_{m}$ for different $2 \times 2$ pile groups. $E_{p} / E_{s}=1000$ and $\xi_{s}=0.05$. Dotted lines to be read on right axis provide a zoomed view.

$\theta$ for large pile-to-pile separation ratios such as $s / d=5,7.5,10,15$, except for small rake angles [28]. However, for small pile-to-pile separation $(L / d=7.5$ and $s / d=2.5$ or $s / d=3.75)$ the rotational kinematic interaction factor $I_{\varphi}$ of inclined piles is smaller than the one corresponding to vertical piles for all rake angles within the range under study.

A minimum cap rotation can be achieved by inclining piles a small rake angle as $\theta=1^{\circ}$ or $\theta=3^{\circ}$ [28]. It might accordingly be inferred that a minimum value of the maximum shear force at the base of the structure $Q_{m}$ could be reached for these rake angles. However, this does not occur (results not shown for the sake of brevity) because even though the rotational kinematic interaction factor $I_{\varphi}$ increases with the rake angle, as shown in Fig. 7, so does the horizontal damping $c_{x x}$ (see Fig. 4) which leads to a reduction of $Q_{m}$ as the rake angle $\theta$ increases.

Regarding the relationship between the geometric and mechanic properties of the foundation, one could think that the geometric point where the extension of the raked pile axes meet above the cap $h_{p}=s /(2 \tan \theta)$ could be close to the center of stiffness of the pile group, computed as 

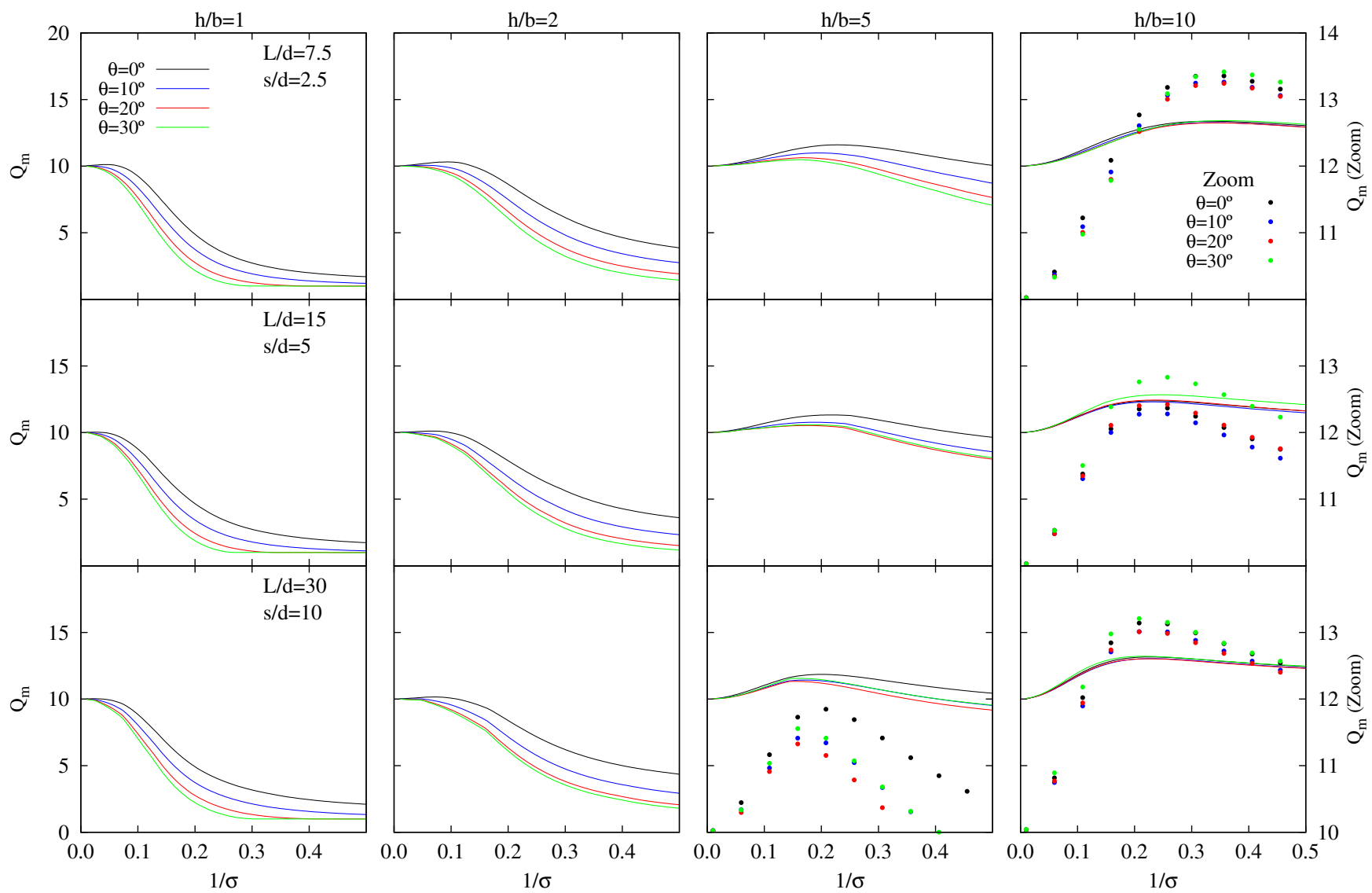

Figure 6: Maximum structural response value $Q_{m}$ for different $3 \times 3$ pile groups. $E_{p} / E_{s}=1000$ and $\xi_{s}=0.05$. Dotted lines to be read on right axis provide a zoomed view.

$\mathscr{D}=-\operatorname{Re}[D]=-\operatorname{Re}\left[-K_{\theta x} / K_{x x}\right]$ (see Fig. 8 ), in which case the seismic response of a structure should be closely related to the relationship $h / h_{p}$ between the height of the center of mass of the building (or corresponding effective modal height $h$ ) and the height of the geometric point $h_{p}$. This would imply different structural behaviour for buildings with heights such that $h / h_{p}>1$ and for those with heights such that $h / h_{p}<1$. In order to test this hypothesis, Figure 9 shows $h_{p} / d$ and $\mathscr{D} / d$ for several configurations of $2 \times 2$ pile groups and rake angles $\theta$ between $0^{\circ}$ and $30^{\circ}$. The values of $\mathscr{D} / d$ have been obtained in two alternative ways: for $a_{o}=0$ (central plot) as well as for those values of the dimensionless frequency $a_{o}$ at which the maximum shear force at the base of the structure $Q_{m}$ occurs (see right plot for $1 / \sigma=0.3$ ). The comparison between the central and right plots of Figure 9 shows that there exist no significant differences between the computation of the centre of stiffness from the static stiffnesses (usual hypothesis) or from the resonant values. The same conclusions applies to all configurations analyzed by the authors.

In the case of vertical piles $\left(\theta=0^{\circ}\right)$ the axes of both piles never meet above the cap so $h_{p} \rightarrow \infty$ 

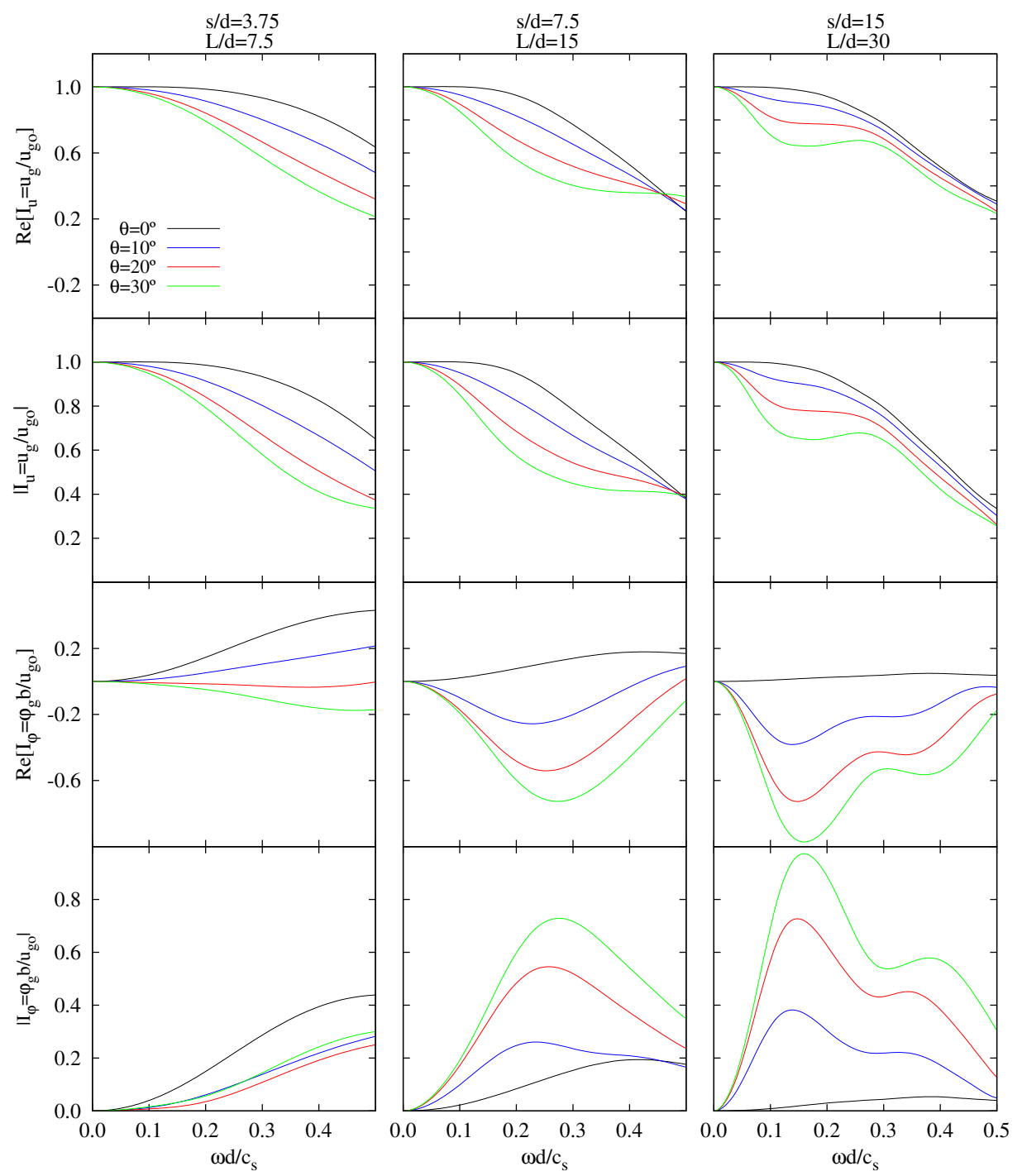

Figure 7: Kinematic interaction factors of different $2 \times 2$ pile groups. $E_{p} / E_{s}=1000$ and $\xi_{s}=0.05$

whereas $\mathscr{D} / d$ takes negative values. From this situation, and as the rake angle increases, $h_{p} / d$ decreases while $\mathscr{D} / d$ increases, even becoming positive. However, they do not cross each other in the range under study. In fact, $\mathscr{D} / d$ and $h_{p} / d$ could only coincide for rake angles over $30^{\circ}$ and very low values of $E_{p} / E_{s}$, which would represent cases with no practical interest.

In order to confirm these observations and show that there is no significant influence on the seismic response in the transition between values of $h / h_{p}$ smaller or greater than one, Figure 10 shows the maximum response $Q_{m}$ of a structure with $h / b=2$ founded on a $2 \times 2$ pile group with inclined elements. In this case (being $b=s$ ), the relationship between the ratio $h / h_{p}$ and the rake angle (also 

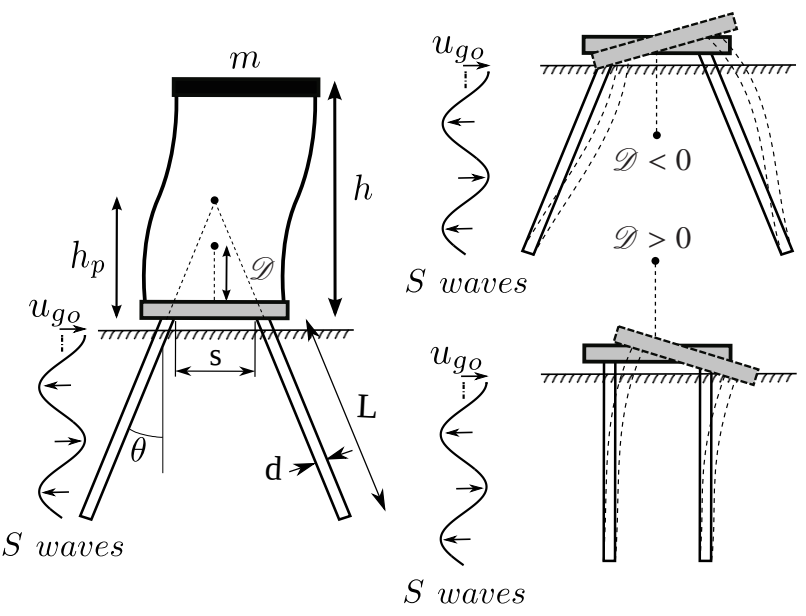

Figure 8: Center of stiffness $\mathscr{D}$ and height of the geometric point $h_{p}$.

shown in the figure) can be expressed as $h / h_{p}=4 \tan \theta$, in such a way that rake angles $\theta$ between $0^{\circ}$ and $25^{\circ} \mathrm{imply}$ ratios $h / h_{p}$ from 0 to 1.865 . Results for different values of $1 / \sigma$ are depicted in this figure. Even thought, for this configuration, a rake angle $\theta=14^{\circ}$ makes the height $h_{p}$ coincide with the height $h$ of the vibrating mass $\left(h / h_{p}=1\right)$, no change of trend in the seismic shear forces is found for $\theta$ above or below $14^{\circ}$. Therefore, in the case of fixed pile-cap connections, this parameter $h / h_{p}$ does not influence the behaviour of the system.
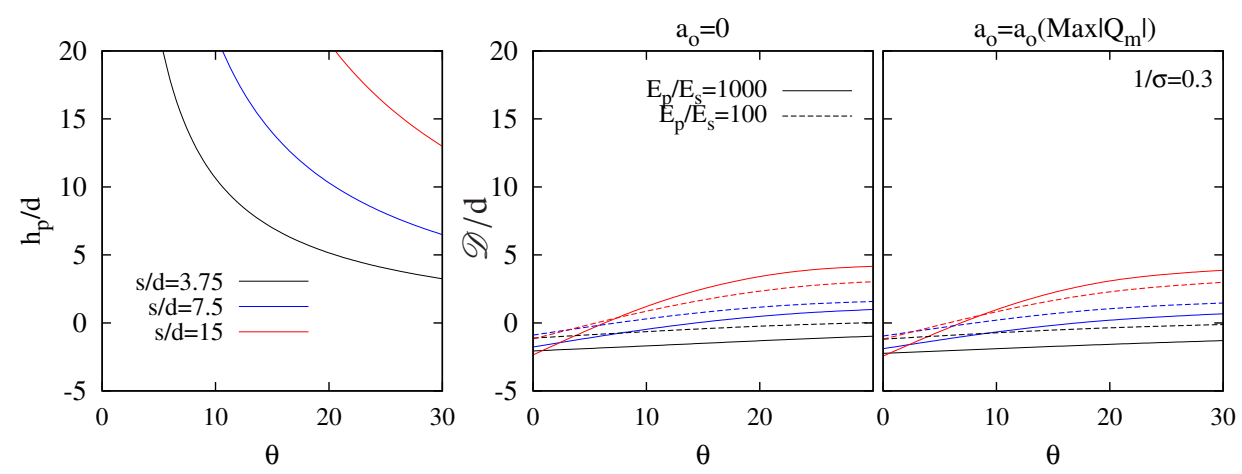

Figure 9: Center of stiffness of $2 \times 2$ pile groups with piles inclined with different rake angles and pile spacing ratios. $\xi_{s}=0.05$.

\subsection{Elastic response spectra}

In this section, for the purpose of illustrating the effects explained before, results in terms of effective system period $\tilde{T} / T$ and damping $\tilde{\xi}$ are used to build modified response spectra that include the 

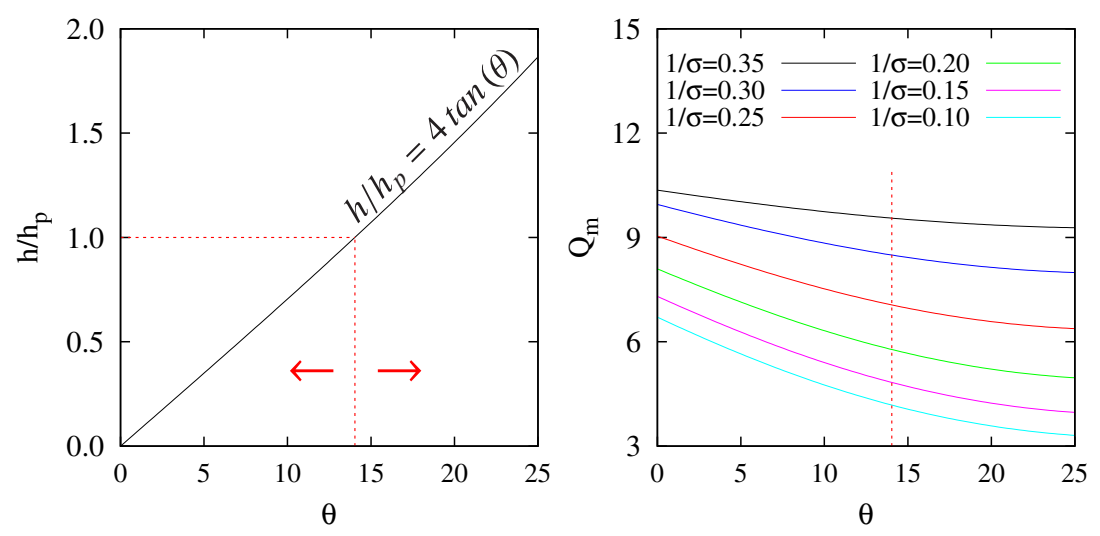

Figure 10: Influence of $h / h_{p}$ on the maximum structural response of a structure with $h / b=2$ supported on $2 \times 2$ pile groups $(b=s)$ with piles inclined with different rake angles. $s / d=7.5, E_{p} / E_{s}=1000$ and $\xi_{s}=0.05$.

influence of pile rake angle $\theta$. This way of representing the structural response has been previously used by other authors such as Veletsos and Meek [2] or Avilés et al. [12].

Firstly, and only in order to verify the validity of the approach of an equivalent SDOF system for the analysis of the seismic structural response, Fig. 11 allows to compare the plots of peak acceleration at the vibrating mass for the 3DOF system against the peak pseudo-acceleration of the equivalent SDOF system, both as a function of its fixed-base fundamental period for the N-S component of the 1940 El Centro earthquake [34] and keeping $1 / \sigma$ constant as by Veletsos and Meek [2]. In this figure, the vertical and the horizontal axes represent the structural pseudo-acceleration $S_{e} / a_{g}$ and the fixed-base fundamental period $T$ of the structure, respectively. For the sake of brevity, this study is performed only for superstructures with different slenderness ratios $(h / b=1,2,5,10)$ supported on several $2 \times 2$ pile groups with pile spacing ratios $s / d=3.75$ and $s / d=15$. Three different values have been taken into account for the wave parameter: $1 / \sigma=0.1,0.2,0.3$. In this case, the rake angle is considered to be $\theta=10^{\circ}$. For pile groups with $L / d=7.5$ the results for the SDOF replacement oscillator reproduce very closely those obtained for the complete system. Nevertheless, minor discrepancies can be observed when $L / d=30$ and $h / b=1$ and 2 .

Secondly, Figure 12 presents elastic response spectra for different configurations of $2 \times 2$ pile groups with inclined elements and with $L / d=7.5, L / d=15$ and $L / d=30$, respectively. Foundation halfwidth $b$, pile slenderness ratio $L / d$ and pile-to-pile separation ratio $s / d$ are kept constant for all cases in the same row. The columns of the figure correspond to the cases with $h / b=10 \cdot(1 / \sigma)=1$, 2 and 3 respectively. This correlation between $h / b$ and $1 / \sigma$ allows to keep the shear wave velocity in the soil $c_{s}$ constant for all cases in a row. It can be seen that, when $L / d=7.5$, the influence of the rake angle increases with $h / b$. However, when $L / d=30$ the influence of the rake angle becomes more appreciable as $h / b$ decreases, while no clear trend is apparent for $L / d=15$. On the other hand, the structural pseudo-acceleration tends to decrease for higher rake angles. This observation is rigorously true along the whole spectrum for $h / b=10 \cdot(1 / \sigma)=1$ and $L / d=7.5$ and 15 . In the other 

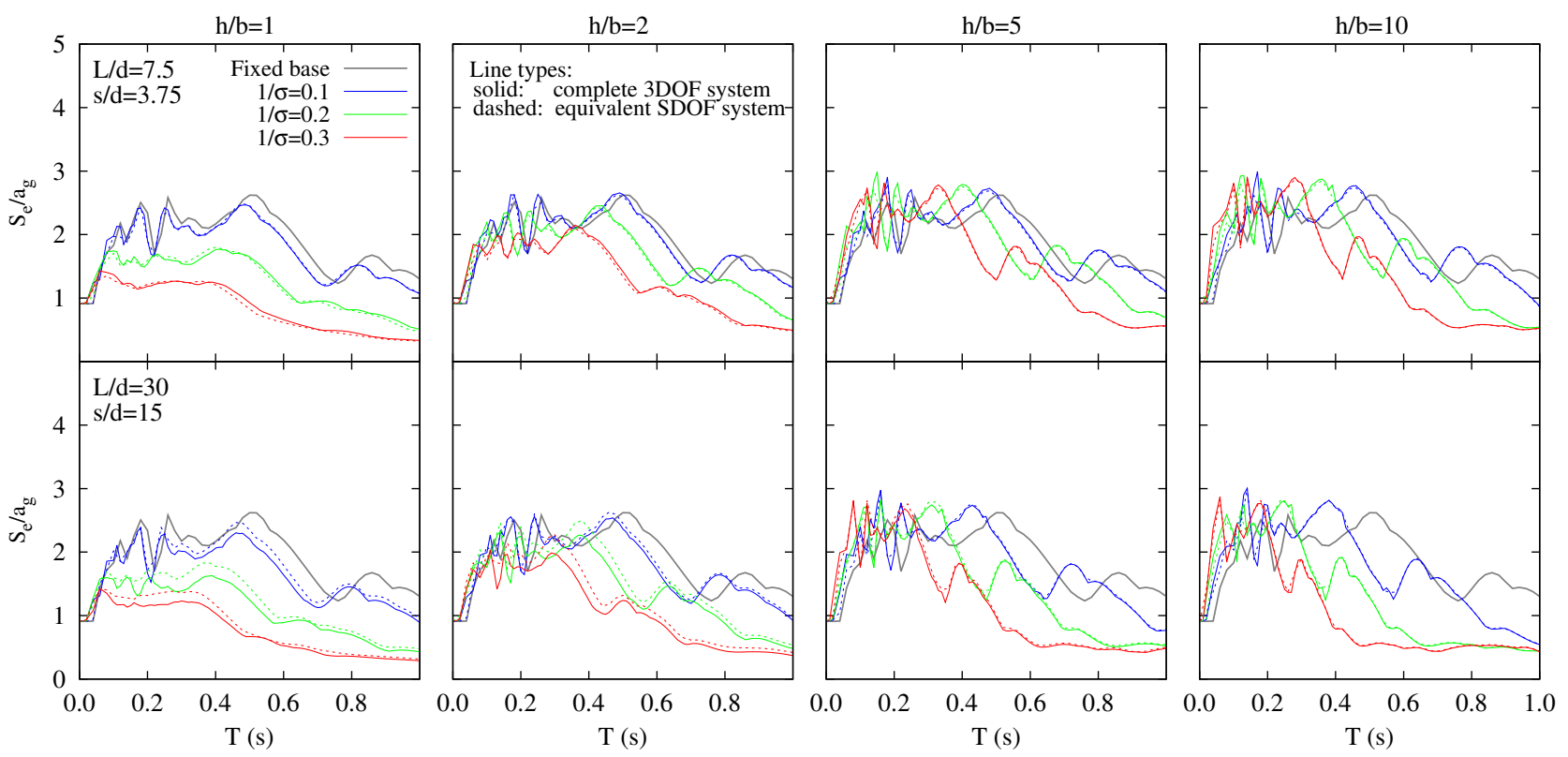

Figure 11: Elastic response spectra corresponding to the 1940 El Centro Earthquake for different $2 \times 2$ pile groups with piles inclined $\theta=10^{\circ}, E_{p} / E_{s}=1000$ and $\xi_{s}=0.05$. SDOF vs 3DOF.

cases, however, there exist values of the fixed-base fundamental period of the structure for which pile inclination can be detrimental. As expected from the results shown in the previous sections, the more slender the superstructure, the less systematic and significant are the beneficial effects of rake angle on the structural response.

Finally, in order to illustrate better the influence of structural height, Fig. 13 presents elastic response spectra of the motion of the vibrating mass of two superstructures with slenderness ratios $h / b=1$ and 2 , respectively and the same fundamental period $T=0.44 \mathrm{~s}$. A clear reduction of the spectral acceleration can be observed as the rake angle increases in both cases. These results are coherent with those provided by Giannakou et al. [25].

\section{Conclusions}

This paper presents an analysis of the influence of the rake angle of piles on the dynamic response of pile-supported structures. To this end, a simple and accurate procedure based on a substructuring model is used to obtain the maximum shear force at the base of the structure $Q_{m}$ (paying particular attention to the differences among the values reached for $Q_{m}$ in relation to $\theta$ ) of an SDOF equivalent system which reproduces the coupled system response within the range where the peak response occurs. A BEM-FEM methodology is used in this paper to obtain the impedance functions and kinematic interaction factors of all configurations under investigation.

Results for 24 different configurations are obtained. The main conclusions drawn from the analysis 

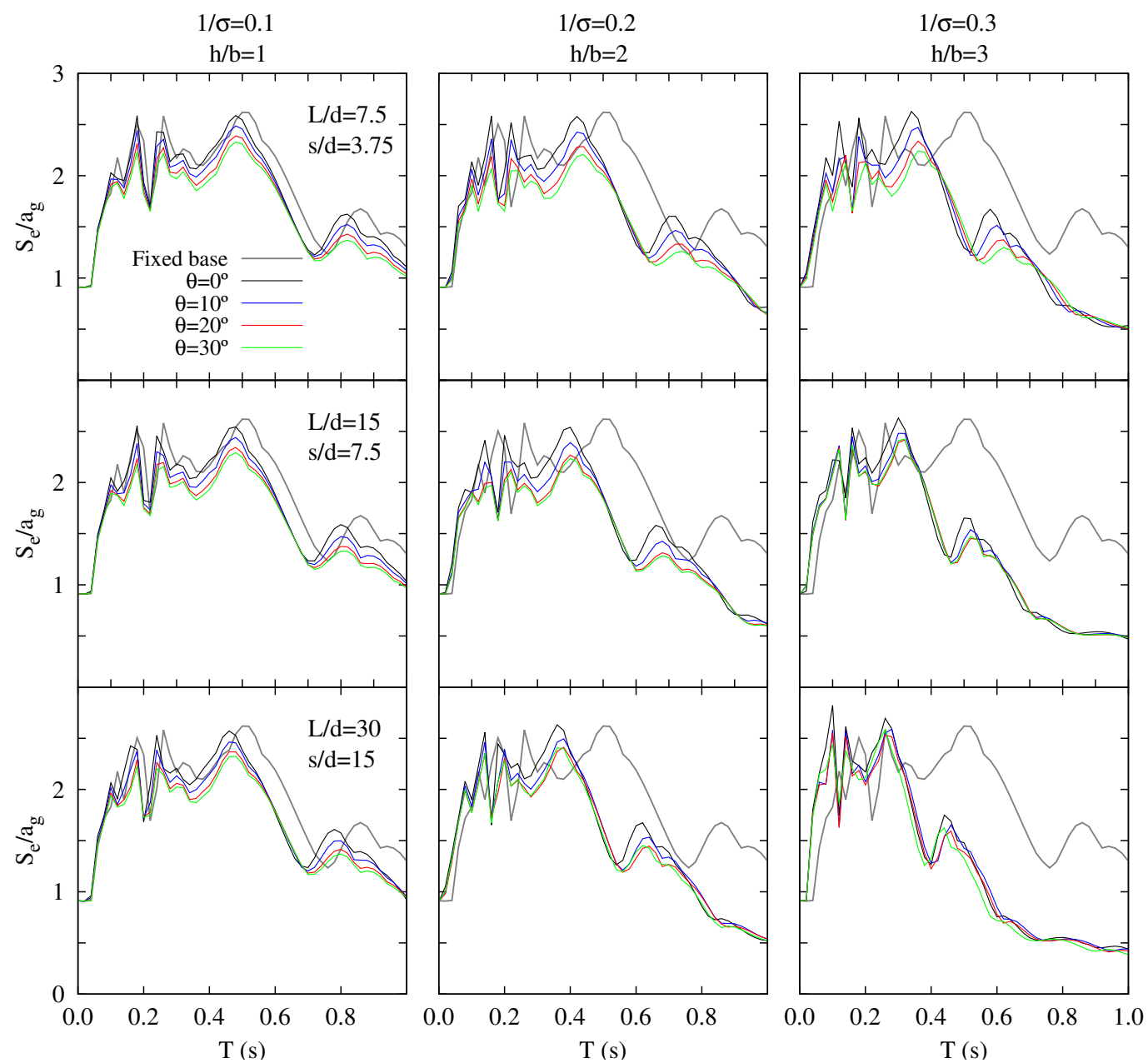

Figure 12: Elastic response spectra corresponding to the 1940 El Centro Earthquake for different $2 \times 2$ pile groups. $E_{p} / E_{s}=1000$ and $\xi_{s}=0.05$.

of the results obtained for the cases under investigation are summarised below:

- For short squat buildings, the effective period $\tilde{T} / T$ is reduced as the rake increases due to the increment of the horizontal stiffness. However, for tall slender structures, $\tilde{T} / T$ generally increases with the rake angle due to a reduction of the rocking impedance, except for close pile spacing.

- The increase of the rake angle leads to lower values of the maximum shear force at the base of the structure $Q_{m}$ when $h / b=1$ or $h / b=2$. However, in the case of slender structures $Q_{m}$ increases with the rake angle.

- The variation of the relationship $h / h_{p}$ (between the height of the center of mass of the building (or corresponding effective modal height $h$ ) and the height of the geometric point where the 

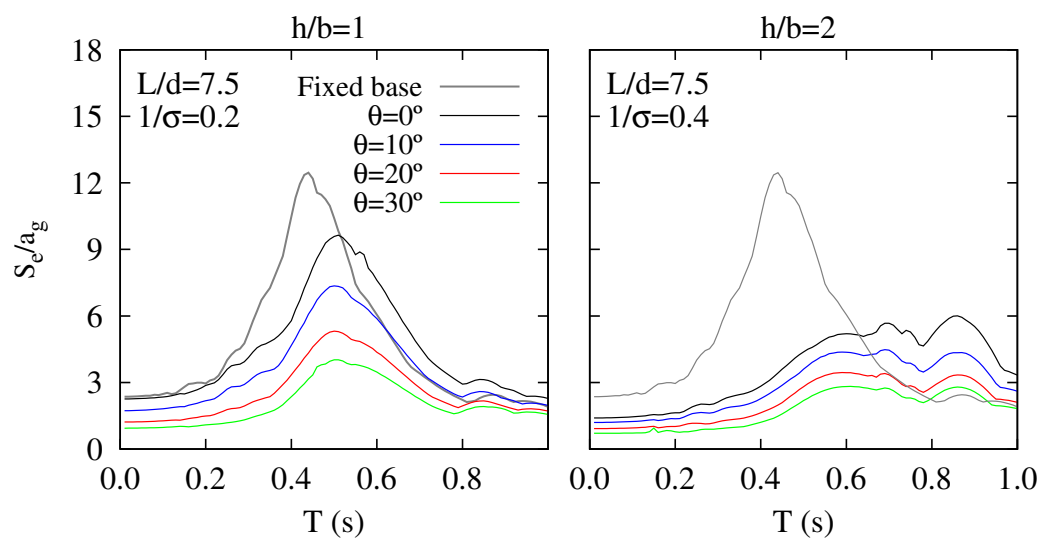

Figure 13: Elastic response spectra of the motion of the mass corresponding to the $1940 \mathrm{El}$ Centro Earthquake a $2 \times 2$ pile group with $s / d=3.75$ being $T=0.44 s . E_{p} / E_{s}=1000$ and $\xi_{s}=0.05$.

extension of the raked pile axes meet above the cap $h_{p}$ ) above or below unity does not imply a change of trend in the structural response presented in terms of maximum shear force at the base of a structure when a fixed pile-cap connection exists. This is due to the fact that, in that case, the height $\mathscr{D}$ of the centre of stiffness of the pile group is not related to $h_{p}$.

- In most cases, a reduction of the spectral acceleration can be observed as the rake angle increases. However, the more slender the superstructure, the less systematic and significant are the beneficial effects of rake angle on the structural response.

\section{Acknowledgements}

This work was supported by the Subdirección General de Proyectos de Investigación of the Ministerio de Economía y Competitividad (MINECO) of Spain and FEDER through research project BIA2010-21399-C02-01 and also by the Agencia Canaria de Investigación, Innovación y Sociedad de la Información (ACIISI) of the Government of the Canary Islands and FEDER through research project ProID20100224. C. Medina is a recipient of a fellowship from the Program of predoctoral fellowships of the University of Las Palmas de Gran Canaria (ULPGC). The authors are grateful for this support.

\section{References}

\section{References}

[1] P. C. Jennings, J. Bielak, Dynamics of building-soil interaction, Bulletin of the Seismological Society of America 63 (1973) 9-48. 
[2] A. S. Veletsos, J. W. Meek, Dynamic behaviour of building-foundation systems, Earthquake Engineering and Structural Dynamics 3 (1974) 121-138.

[3] A. S. Veletsos, V. V. D. Nair, Seismic interaction of structures on hysteretic foundations, Journal of the Structural Division, ASCE 101 (1975) 109-129.

[4] J. Bielak, Modal analysis for building-soil interaction, Journal of the Engineering Mechanics Division, ASCE 102 (1976) 771-786.

[5] J. E. Luco, Linear soil-structure interaction, Technical Report UCRL-15272, Lawrence Livermore National Laboratory, Livermore, California, 1980.

[6] J. P. Wolf, Dynamic soil-structure interaction, Englewood Cliffs, (NJ); Prentice-Hall, 1985.

[7] J. Bielak, Dynamic behaviour of structures with embedded foundations, Earthquake Engineering and Structural Dynamics 3 (1975) 259-274.

[8] J. Avilés, L. E. Pérez-Rocha, Evaluation of interaction effects on the system period and the system damping due to foundation embedment and layer depth, Soil Dynamics and Earthquake Engineering 15 (1996) 11-27.

[9] M. I. Todorovska, Effects of the depth of the embedment on the system response during buildingsoil interaction, Soil Dynamics and Earthquake Engineering 11 (1992) 111-123.

[10] M. I. Todorovska, M. D. Trifunac, Radiation damping during two-dimensional in-plane buildingsoil interaction, Technical Report 91-01, Department of Civil Engineering. University of Southern California, 1991.

[11] M. I. Todorovska, M. D. Trifunac, The system damping, the system frequency and the system response peak amplitudes during in-plane building-soil interaction, Earthquake Engineering and Structural Dynamics 21 (1992) 127-144.

[12] J. Avilés, L. E. Pérez-Rocha, Effects of foundation embedment during building-soil interaction, Earthquake Engineering and Structural Dynamics 27 (1998) 1523-1540.

[13] J. Avilés, M. Suárez, F. J. Sánchez-Sesma, Effects of wave passage on the relevant dynamic properties of structures with flexible foundations, Earthquake Engineering and Structural Dynamics 31 (2002) 139-159.

[14] J. H. Rainer, Simplified analysis of dynamic structure-ground interaction, Canadian Journal of Civil Engineering 2(3) (1975) 345-356.

[15] A. M. Kaynia, S. Mahzooni, Forces in pile foundations under seismic loading, Journal of Engineering Mechanics 122(1) (1996) 46-53.

[16] G. Mylonakis, A. Nikolaou, G. Gazetas, Soil-pile-bridge seismic interaction: kinematic and inertial effects. part i: soft soil, Earthquake Engineering and Structural Dynamics 26 (3) (1997) 337-359. 
[17] J. Guin, P. K. Banerjee, Coupled soil-pile-structure interaction analysis under seismic excitation, J Struct Eng 124 (1998) 434-444.

[18] H. Aguilar, J. Avilés, Influencia de pilotes de fricción en la interacción dinámica suelo-estructura, Revista Internacional de Métodos Numéricos para Cálculo y Diseo en Ingeniería 19,1 (2003) 3-18.

[19] A. Maravas, G. Mylonakis, D. Karabalis, Dynamic characteristics of simple structures on piles and footings, in: Proceedings of 4th International Conference on earthquake geotechnical engineering, no. 1672, Thessaloniki, Greece, 2007.

[20] E. N. Rovithis, K. D. Pitilakis, G. Mylonakis, Seismic analysis of coupled soil-pile-structure systems leading to the definition of a pseudo-natural ssi frequency, Soil Dynamics and Earthquake Engineering 29 (2009) 1005-1015.

[21] E. N. Rovithis, K. D. Pitilakis, G. Mylonakis, A note on a pseudo-natural ssi frequency for coupled soil-pile-structure systems, Soil Dynamics and Earthquake Engineering 31 (2011) 873-878.

[22] S. Carbonari, F. Dezi, G. Leoni, Seismic soil-structure interaction in multi-span bridges: Application to a railway bridge, Earthquake Engineering and Structural Dynamics 40 (2011) 1219-1239.

[23] C. Medina, J. J. Aznárez, L. A. Padrón, O. Maeso, Effects of soil-structure interaction on the dynamic properties and seismic response of piled structures, Soil Dynamics and Earthquake Engineering 53 (2013) 160-175.

[24] N. Gerolymos, A. Giannakou, I. Anastasopoulos, G. Gazetas, Evidence of beneficial role of inclined piles: observations and summary of numerical analyses, Bulletin of Earthquake Engineering 6(4) (2008) 705-722.

[25] A. Giannakou, N. Gerolymos, G. Gazetas, T. Tazoh, I. Anastasopoulos, Seismic behaviour of batter piles: elastic response, Journal of Geotechnical and Geoenvironmental Engineering, ASCE 136(9) (2010) 1187-1199.

[26] J. Guin, Advances in soil-pile-structure interaction and non-linear pile behavior, Ph.D. thesis, State University of New York at Buffalo, 1997.

[27] M. Sadek, I. Shahrour, Three-dimensional finite element analysis of the seismic behavior of inclined micropiles, Soil Dynamics and Earthquake Engineering 24(6) (2004) 473-485.

[28] C. Medina, L. A. Padrón, J. J. Aznárez, A. Santana, O. Maeso, Kinematic interaction factors of deep foundations with inclined piles, Earthquake Engineering and Structural Dynamics doi: 10.1002/eqe.2435 (2014).

[29] L. A. Padrón, J. J. Aznárez, O. Maeso, BEM-FEM coupling model for the dynamic analysis of piles and pile groups, Engineering Analysis with Boundary Elements 31 (2007) 473-484.

[30] L. A. Padrón, J. J. Aznárez, O. Maeso, A. Santana, Dynamic stiffness of deep foundations with inclined piles, Earthquake Engineering and Structural Dynamics 39(12) (2010) 1343-1367. 
[31] L. A. Padrón, J. J. Aznárez, O. Maeso, 3-D boundary element - finite element method for the dynamic analysis of piled buildings, Eng Anal Bound Elem 35 (2011) 465-477.

[32] G. Gazetas, K. Fan, T. Tazoh, K. Shimizu, M. Kavvadas, N. Makris, Seismic pile-group-structure interaction, Geothecnical Specialty Publication, ASCE 34 (1992) 56-93.

[33] J. P. Stewart, R. B. Seed, G. L. Fenves, Seismic soil-structure interaction in buildings. ii: Empirical findings., Journal of Geotechnical Engineering, ASCE 125(1) (1999) 38-48.

[34] A. K. Chopra, Dynamics of structures. Theory and applications to earthquake engineering., Prentice-Hall (NJ), 2001. 